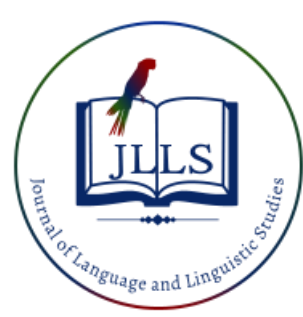

Available online at www.jlls.org

JOURNAL OF LANGUAGE AND LINGUISTIC STUDIES

ISSN: $1305-578 \mathrm{X}$

Journal of Language and Linguistic Studies, 17(2), 697-705; 2021

\title{
Understanding language acquisition: Neural theory of language
}

\author{
Aslı Aktan-Erciyes ${ }^{\text {a } 1 \text { iD }}$ \\ APA Citation: \\ ${ }^{a}$ Kadir Has University, İstanbul, Turkey \\ Aktan-Erciyes, A. (2021). Understanding language acquisition: Neural theory of language. Journal of Language and Linguistic Studies, \\ 17(2), 697-705. Doi: 10.52462/jlls.48 \\ Submission Date: $15 / 02 / 2021$ \\ Acceptance Date: 06/05/2021
}

\begin{abstract}
This paper aims to discuss old and contemporary perspectives in understanding language acquisition taking into account the neural theory of language. Discussing a recent theory by Kuhl (2010), neural substrates of first language learning will be put forward (Berwick et al., 2013). Neural substrates of phonetic learning, word learning, sentence processing, and syntax development are separately discussed. As a novel window to look into language learning in a greater detail, second language learning in relation to the theories of language acquisition is further discussed. Second language learning and dual vs. single coding structure relating to language acquisition are discussed in relation to the theories that have previously been explained. Finally, a discussion of contemporary issues in understanding both first and second language acquisition in relation to bilingualism is presented. In sum, investigating language acquisition requires a multi-disciplinary approach taking psychology, linguistics, and cognitive neuroscience of language into account is necessary.
\end{abstract}

Keywords: language acquisition; neural substrates; native language; second language dual vs. single coding

\section{Introduction}

Language acquisition has always attracted attention from various disciplines, including philosophy, psychology, and neuroscience. The links between mind and thought have been made prominently distinctive with the theories explaining the acquisition of language. In the last half of the 20th century, there have been important advances in explaining language. According to Skinner (1957 as cited in Kuhl, 2000) language developed as a result of conditioning as a function of external reinforcement. On the other hand, in his review (1957 as cited in Kuhl, 2000) of Verbal Behavior by Skinner, he proposes the famous "language faculty" and proposes the ways human language can take form based on the limitations that are innately determined. On the other hand, Chomksy proposes that infants have innate constraints for a language where they build upon "universal grammar" and "universal phonetics". These two approaches point to different critical elements regarding the theory of language acquisition. According to Skinner's view, innate information is not required; instead, developmental change by itself takes care of the language acquisition with the help of reward mechanisms (operant conditioning). However, Chomsky has proposed that infants' innate capability of language was a core faculty and that language development actually consists of the advancement of the language module coupled with environmental input.

\footnotetext{
${ }^{1}$ Corresponding author.

E-mail address: asli.erciyes@khas.edu.tr
} 
The above debate has been tested vastly by research in the field especially based on the investigation based on infants. Actually, infants' perception of the phonetic units of speech and detection of words from cues that take place in the speech support a very different view (Kuhl, 2000). This view suggests that the learning that takes place in early language acquisition cannot be explained by Skinner's terms. However, the other alternative that language acquisition pursues a selective process is not supported either. In this alternative, language input was suggested to be processed by innately defined structures. The new view proposes that infants follow a different style of learning where the language input is actually mapped exclusively by the neural structures (Kuhl, 2004).

\section{A new view of language acquisition: Native language neural commitment}

There are several principles that are postulated for the new model. First of all, the ability to correctly parse speech at the initial perception is universal but it is not a domain-specific or speciesspecific process. Research within early infancy shows that infants have tremendous ability to correctly parse speech at the phonetic level and also this ability is evident and universal across languages (Gross et al., 1998). Early models of speech perception were selectionist (Eimas, 1974 as cited in Kuhl, 2000). Developmental research provided support for this selectionist view. For instance, Werker \& Tees (1984) found that although infants were able to discriminate non-native phonetic contrasts at 6 months of age, they were not able to do so when they were at 12 months old. However, the fact that infants did not lose the ability to discriminate non-native sounds completely does not change the assumptions and propositions of the selectionist view. Additionally, infants possess learning strategies that help them map their repertoire on the language input via detecting patterns in language. They are also able to parse out and use probabilistic cues presented in contextual language and identify higherorder elements. The next principle is about the language experience. This principle suggests that language experience results in a change in infants' discriminative preferences, as well as by altering the perception aids correct mapping along. This is one of the most crucial properties of the model. The effect is also called as "magnet effect". This effect is observed when proper representatives of the phonetic category, which can be regarded as prototypes, are presented in the speech. Another important factor is the quality of input the infant experiences. Motherese, which can be defined as a caregiver's speech that resembles baby talk that is high in pitch, is a crucial component of the theory. Exaggerated stress and high pitch, which are properties of child-directed speech are be preferred over adult-directed speech by infants (Fernald \& Kuhl, 1987). The existence of high pitch in motherese helps infants to differentiate phonetic units. To give an example mothers seem to direct infants in a way that aids their learning. When mothers are introducing new words, for instance, they repeat the word in stereotyped forms ("Where is -__ ? See the __, That's a __ "); where each and every one of them highlights the items). They also represent words in a variety of contexts, such as in a book reading instance as well as when an object is in sight.

Last but not the least; the model proposes that a critical or sensitive period for language acquisition depends on experience as well as time. When we claim that children learn the language more naturally and easily compared to adults; this thinking creates a paradox that adults have more advanced cognitive skills. The studies involving speech suggest an alternative explanation. According to the Native Language Magnet Model (Native Language Neural Commitment - Model), mental maps are formed for speech, and this process builds the neural structure. ERP measures of brain activity show that the left-hemisphere shows effects for native-language sounds in mismatched negativity (a measure of the signal which shows a change in repetitive/expected sound pattern) indicating the existence of a neural infrastructure. The model proposes that neural commitment to learned structure (native language) may interfere while processing sound patterns that do not conform to learned ones. Therefore, initial learning can alter future learning. 
To sum up, the model posits that infants are neither "tabula rasa"s that Skinner has proposed nor they are innate grammarians that Chomsky has put forth. Instead, infants have perceptual biases/inclinations to parse phonetic units without having initial descriptions for them. Additionally, infants use complex inherent learning strategies for learning the language. Moreover, adults when talking to infants, use speech that assists the brain mapping of language. This way of learning also accommodates perceptual learning.

\section{Neural substrates of language acquisition}

\subsection{Neural substrates of phonetic learning}

Language acquisition research especially in infancy focuses mostly on phonetic perception. Phonetic perception at infancy refers to infants' perceiving vowels and consonant terms that build up a word. With the help of the noninvasive imaging techniques that allow gathering data securely even at the earliest stages in life, critical tests on language acquisition were made possible. Such brain measures provide substantial information related to phonetic learning (Kuhl, 2004).

Studies demonstrate that infants possess a capacity to differentiate between phonetic contrasts in all world languages which is evident universally (Eimas et al, 1971 as cited in Kuhl \& Rivera-Gaxiola, 2008). However, this capacity changes by the language experience the infant is being exposed to, starting from 6 months of age. At this period of transition, two important changes occur as reported by studies. First of all, first language phonetic abilities are found to increase significantly (Cheour et al. 1998, Sundara et al, 2006), whereas the ability to discriminate phonetic contrasts which are not associated with native language seem to decrease (Werker \& Tees, 1984, Cheour et al., 1998).

Around 12-months of age, the infant brain is suggested to no longer be universally prepared for all languages, rather it is ready and more inclined to acquire the language to which the infant has been exposed to. For instance, Rivera-Gaxiola et al. (2005) measured ERP figures for 7- and 11-month-old English-speaking infants in response to both Spanish and English stimuli. Infants' responses to nonnative contrasts which indicate the discrimination ability of native vs. non-native sounds was related with vocabulary performance starting from 18- to 30-months of age. Infants who were less efficient in discriminating native vs. non-native sounds had larger vocabulary growth. This indicates that better discrimination of non-native contrasts indicates that the infant is still not specialized in his/her own native language enough.

\subsection{Neural substrates of word learning}

Between 18 and 24 months of age, a word spurt (i.e., sudden increase of vocabulary) occurs (Ganger \& Brent, 2004). At six months, infants recognize their own names or 'mommy' as a word segmentation cue (Bortfeld et al., 2005). Six-month-old infants were presented short passages and familiarized with the stimuli. Infants' preferential looking times indicated that they are able to recognize the presented new word after the familiar name but not after the novel name. This indicates that as early as 6 months, infants have a capacity to segment a fluent and continuous speech.

Another important question in the field is that how infants perceive new or novel words in ongoing speech with the fact that speech is continuous and there are no acoustic/indicative silences between the words. By 8 months, there are different strategies that infants adopt to identify specific words within the speech. For instance, infants perceived adjacent syllables which probabilistically occur more in a language as word-like units within the presentation of nonsense syllables. In other words, as infants are exposed to more sound-couples, they tend to get used to hearing them. Empirical research showed that both probabilities of sound following each other between adjacent syllables as well as stress cues 
(for instance stress is on the first syllable in English) made it possible for infants to identify words in speech (Saffran, 2003; Nazzi et al., 2006; Newport \& Aslin, 2004).

Word recognition in the brain is evidenced as early as 9 months by ERP studies. ERP measurements in response to words that look at word familiarity show that as early as 9 months there is an indication of familiarity. For word meaning on the other hand, ERP studies show that by $13-17$ months, infants display differences for known vs. unknown words.

There are also individual differences regarding language proficiency evidenced by neural activity. For instance, children who have larger vocabularies showed more pronounced N200 responses for known words compared to unknown words in the left temporal and parietal lobe. On the other hand, children with smaller vocabulary showed more broadly distributed brain activation. Another study investigated ERPs to examine new word learning in 20-month-old toddlers. Children were presented with novel objects coupled with non-words in order to investigate word learning. ERP signals indicate that while children were presented with non-words they show similar activation that they would show to known words. The results suggest that new words are associated with similar neural reactions like as known words.

\subsection{Neural substrates of sentence processing}

In order for a child to understand sentences and start to produce of his/her own, first, the child must have phonological abilities that enable him/her to segment speech into words in order to extract word meaning. As Friederici et al. (2006) has proposed human language is defined by hierarchically structured sequences. After 12-months of age, children's ERP data in response to violations in syntactic and semantic components with regard to sentence processing show that they resemble adultlike patterns (Oberecker et al. 2005). Silva-Pereyra et al. (2005) measured ERP signals for 3- to 4year-old children while listening to both semantic and syntactic anomalies compared to control sentences. Results indicated that ERP signals were not only distributed more broadly compared to adults, but their latencies were also later.

\subsection{A neural theory of language: Neural mechanisms for syntax and hierarchical structures}

As described before, human language contains hierarchical structures which result from various processing operations. It is evident that the processing of complex sentences involves Broca's area (BA44) in the inferior frontal gyrus IFG). There are two dorsal pathways involved in language; the first one is the pathway between the posterior superior temporal cortex (pSTC) to the Broadman area (BA44) that supports core syntactic computations. The second dorsal pathway is between Premotor Cortex (PMC) and pSTC which subserves sensory-motor interface. For semantic processes, ventral pathways are at charge. Specifically, pars triangularis (BA45) in the inferior frontal cortex and portions of the temporal cortex (Berwick et al, 2012). In a study, Musso et al. (2003) instructed German speakers to learn either 'real' or 'unreal' grammatical rules of different languages (Italian or Japanese). During the learning task, fMRI results showed that there was increased activation in Broca's area which was specific to 'real' language. Findings suggest a role for Broca's area in the processing of syntax. Speakers were also able to learn 'unreal' grammatical rules. However, at those instances, brain regions other than Broca's area were activated. This might be an indication of language processing can be dissociated from other cognitive processes in a neural sense.

The neural theory of language (NTL) is a project which is carried out in the perspectives of interdisciplinary research in an effort to answer the question of how the brain computes the mind. The basic questions asked were "how the brain supports thought and language?" "How language and thought are related to other neural systems" "what are the computational properties of neural 
systems?" For this purpose, a multi-disciplinary view is adopted, taking computer-science, linguistics, cognitive science, and psychology into account. The project has special importance due to the fact that, on one hand, linguistics presents a powerful theoretical framework through empirical data which do not have neurocognitive components and on the other hand cognitive neuroscience of language has developed experimental methods to study brain structure involving language (Grimaldi, 2012). Advances in the imaging techniques allow tremendous crucial data to be extracted even at the earliest stages of development.

The study of second language acquisition and bilingualism shed light to important issues in language acquisition. The following section is devoted to neural bases of first and second language acquisition.

\subsection{Discussion on the neural bases of first and second language learning: One mind two languages}

The study of second language acquisition is both an intriguing issue and a prosperous in terms of endless possible aspects in the field of linguistics, psychology, and cognitive neuroscience of language. Although many advantages of bilingualism in today's world are being suggested, it's no more than 60 years ago when Adler (1977 as cited in Titone, 1989) suggests about the bilingual adult and child "Often (bilinguals) have split minds... he is neither here nor there: he is a marginal man". Luckily, the view about bilingualism has changed dramatically into a positive direction in today's world.

Genesee, Nicoladis, and Paradis (1995) argue that there is an early differentiation of the two languages if exposure to L2 starts before 5 years of age. Genesee et al. examined language differentiation of five bilingual children between the ages of $1 ; 10$ and $2 ; 2$ by observing them with each parent separately and together on different occasions. The results indicate that although these children displayed code mixing, they were obviously able to differentiate between both of the languages. The researchers argue that code-mixing instances could not be a sign of the existence of a single structure for both languages at stages as early as 1 year of age, and claim that children do have an early differentiation in their minds pertaining to the languages they are exposed to. Meisel (1989) suggests that this differentiation might occur as early as 2 years of age if the child acquires both languages simultaneously.

The acquisition order of the two languages, whether simultaneous or sequential, has a bearing on the relationship between the two languages. Findings from studies of simultaneous acquisition or acquisition of 'multiple first languages' (De Houwer, 1995, Meisel, 2004) can be summarized as follows: grammatical development in the two languages is differentiated early, development occurs through the same sequences as in monolingual acquisition but not at the same rate, and as a result, grammatical knowledge in each language is no different than that of a monolingual (Meisel, 2007).

In sequential bilingualism, however, an acquisition may result in partial success in terms of grammatical development when one of the languages of a bilingual is the weaker (i.e., the child talks less in) and the other the stronger language. In such cases, children's acquisition of the L2 (second language) is argued to resemble adult L2 acquisition rather than multiple L1 (first language) acquisition (Meisel, 2007). Some properties of the weaker language include "(1) omission of obligatory elements, (2) problems with inflectional morphology, and (3) deviant word order patterns" (Meisel, 2007, p.500).

L1 and L2 acquisition differ in many ways in different stages of attainment. For example, in the initial stage of L2 acquisition, L2 utterances are longer than L1 utterances in L1 acquisition (Meisel, 2007). When the course of acquisition is compared, L1 happens really fast but the rate of L2 
development is slower. There is greater variability across learners of L2 while there is not much variation for L1. Additionally, only a small percentage of L2 learners can reach native-like proficiency. (Meisel, 2007; White \& Genesee, 1996).

One of the most studied issues in second language acquisition is the structure of coding schema for each language. Researchers disagree about how many linguistic systems bilingual children have a unitary one or a dual one. Studies involving imaging techniques that focuses on the neural basis of first and second language show that the long-held assumption that L1 and L2 are represented in different brain regions has not been confirmed. Recent evidence suggests that L1 and L2 are processed by the same neural infrastructures. A theory by Ullman (2001) suggests that grammatical knowledge for L2 is more of a declarative type rather than an implicit one as in the case of L1. These two types of knowledge, implicit and declarative are governed by different neural systems. For implicit knowledge, left frontal-basal ganglia is evident, on the other hand for declarative knowledge, left temporal areas are involved. On contrary, brain imaging studies offer a valuable opportunity to assess the representations of L2 which is contradictory to Ullman's hypothesis (Wartenburger et al, 2003; Briellmann et al. 2013). During grammatical tasks in bilinguals' activation in regions involved in grammatical processing (Broca's area, basal ganglia) were involved comparable level for both languages (L1, L2). The results also indicated that AoA (age of acquisition) and proficiency were important variables in brain activation in bilinguals.

The view that L2 acquisition is not the same as L1 in certain aspects has also been put forward by Bley-Vroman in the Fundamental Difference Hypothesis (Bley-Vroman, 2009) which suggests that L2 acquisition differs from an L1 acquisition in terms of 'reliability' and 'convergence'. The L1 acquisition is reliable since children are always successful in language learning, however, L2 learning has 'unreliability property' since not all individuals end up having the same level of competence although exposure to and usage of L2 might be of the same level. As for the convergence, L1 children end up with language systems similar to those of others in their speech community, whereas L2 acquirers who might be from different language backgrounds (having different grammatical structures) cannot achieve full convergence. Although L2 children, after a few years of sustained L2 exposure, reach general success, the process by which they acquire L2 may not be a replica of L1 acquisition. Child L2 acquisition resembles both $\mathrm{L} 1$ acquisition and adult $\mathrm{L} 2$ acquisition.

In a similar vein, in her Domain by Age model, Schwartz, (2003) has proposed that there are differences in terms of acquisition between different domains and suggests that for syntax, child L2 acquisition is more like adult L2 acquisition but when inflectional morphology is considered, it is more like $\mathrm{L} 1$ acquisition.

As can be seen, the relationship between the two languages is a complex issue determined by a multiplicity of factors such as $\mathrm{AoO}$ (age of onset), an order of acquisition, amount of exposure, the status of the two languages in the community, whether one is weak and the other is dominant, and more. Since a thorough analysis of the question is beyond the scope of this study, this brief summary will serve as a background for a consideration of a sample of the large body of research on the effects of L1 on L2 and L2 on L1.

Support for NLNC theory is backed up by the following evidence: (1) L2 learning studies and (2) language training studies. For instance, in acquiring an L2, some phonetic distinctions might be more difficult to discriminate (e.g., the difficulty of yr-ly distinction for native speakers of Japanese when learning English) (Flege et al, 1995; Lively et al., 1994). It was hypothesized in the studies that for Japanese people required a new map/structure that is more appropriate for English. Relatedly, training research suggests that exaggerating foreign language contrast is an effective training method; thus, listeners need to be exposed to the right kind of listening experience (Pisoni, 1993). The features - 
acoustic cues, mass listening experience- shown to aid second language learning are interestingly the same as motherese provides infants. This is one of the tenets put forward by NLNC. Early in life, interference effects are minimal, thus it is easy for infants to form two mappings. However, a second language learned later in life (around puberty or later) results in a form of separation of two systems to in order to overcome the interference. An fMRI study investigating and comparing the activation areas for two languages in adults, showed that bilinguals who acquired both languages early have overlapping activated areas while processing these languages, whereas for those who acquired the second language later in life, the activation areas do not overlap and regions are distinct for the two languages (Kim et al, 1997).

\section{Conclusion}

Understanding language acquisition requires a multi-disciplinary approach taking psychology, linguistics, and cognitive neuroscience of language into account. Perspectives that encompass all of the above disciplines provide a wider and a more decent understanding of language. In understanding language acquisition both native and second language acquisition might be informative. Therefore, investigating child as well as adult L2 learners highlight lexical competence (Çakmak \& Merç, 2021)

Imaging techniques that allow data being gathered early in life provide crucial information for both acquisition and transitionary information regarding language. Again, a multi-disciplinary approach to data will benefit various fields; including language-related research, and shed light on the understanding of theories of language.

Regarding the dual vs. single structure of language, it is evident that there is an inclination to rely on a single structure depending on the rate of proficiency in each language and age of onset as important determinants. The Threshold theory first put forward by Skutnabb-Kangas (1981) suggests that the development of two or more languages in a balanced bilingual person moves through three levels for the proficiency. For positive cognitive advantages to be experienced, people should pass two thresholds. This is actually in line with the age of onset (the earlier the better) and level of proficiency as key determinants of the structure of language in mind. A considerable amount of data involving imaging support the idea that both the level of proficiency and the onset of language learning.

\section{References}

Berwick, R. C., Friederici, A. D., Chomsky, N., \& Bolhuis, J. J. (2013). Evolution, brain, and the nature of language. Trends in Cognitive Sciences, 17(2), 89-98.

Briellmann, R. S., Saling, M. M., Connell, A. B., Waites, A. B., Abbott, D. F., \& Jackson, G. D. (2004). A high-field functional MRI study of quadri-lingual subjects. Brain and Language, 89(3), 531-542.

Bortfeld, H., Morgan, J. L., Golinkoff, R. M., \& Rathbun, K. (2005). Mommy and me: Familiar names help launch babies into speech-stream segmentation. Psychological science, 16(4), 298-304.

Bley-Vroman, R. (2009). The evolving context of fundamental difference hypothesis, Studies in Second Language Acquisition, 31, 175-198.

Cheour, M., Ceponiene, R., Lehtokoski, A., Luuk, A., Allik, J., Alho, K., \& Näätänen, R. (1998). Development of language-specific phoneme representations in the infant brain. Nature neuroscience, 1(5), 351-353.

Çakmak, C. T., \& Merç, A. (2021). Turkish EFL Learners' Lexical Competence and Performance. Journal of Language and Linguistic Studies, 17(2), 946-964. 
De Houwer, A. (1995). Bilingual language acquisition. In (Eds.) Fletcher, P. \& MacWhinner, B. Handbook of child language. London: Basil Blackwell.

Fernald, A., \& Kuhl, P. (1987). Acoustic determinants of infant preference for motherese speech. Infant Behavior and Development, 10(3), 279-293.

Flege, J. E., Takagi, N., \& Mann, V. (1995). Japanese Adults can Learn to Produce English/I/and/1/Accurately. Language and Speech, 38(1), 25-55.

Friederici, A. D. (2006). The neural basis of language development and its impairment. Neuron, 52(6), 941-952.

Ganger, J., \& Brent, M. R. (2004). Reexamining the vocabulary spurt. Developmental Psychology, 40(4), 621-632.

Genesee, F., Nicoladis, N. \& Paradis, J. (1995). Language differentiation in early bilingual development. Journal of Child Language, 22, 611-631.

Goodsitt, J. V., Morgan, J. L., \& Kuhl, P. K. (1993). Perceptual strategies in prelingual speech segmentation. Journal of Child Language, 20(02), 229-252.

Grimaldi, M. (2012). Toward a neural theory of language: old issues and new perspectives. Journal of Neurolinguistics, 25(5), 304.

Gross, N., Judge, P. C., Port, O., \& Wildstrom, S. H. (1998). Let's talk: Speech technology is the next big thing in computing. Will it put a PC in every home. Business Week, February, 23, 61-80.

Kim, K. H., Relkin, N. R., Lee, K. M., \& Hirsch, J. (1997). Distinct cortical areas associated with native and second languages. Nature, 388(6638), 171-174.

Kuhl, P. (2000). A new view of language acquisition. Proceedings of National Academy of Science, 97(22), 11850-11857.

Kuhl, P. (2004). Early language acquisition: cracking the speech code. Nature Reviews Neuroscience, 5(11), 831-843.

Kuhl, P., \& Rivera-Gaxiola, M. (2008). Neural substrates of language acquisition. Annual. Review Neuroscience., 31, 511-534.

Lively, S. E., Pisoni, D. B., Yamada, R. A., Tohkura, Y. I., \& Yamada, T. (1994). Training Japanese listeners to identify English/r/and/l/. III. Long-term retention of new phonetic categories. The Journal of the Acoustical Society of America, 96(4), 2076.

Meisel, J. M. (2004). The bilingual child. In T. K. Bhatia \& W. C. Ritchie (Eds.), The handbook of bilingualism (pp. 91-113). Oxford: Blackwell Amsterdam: Benjamins.

Meisel, J.M. (2007). The weaker language in early child bilingualism: Acquiring a first language as a second language?, Applied Psycholinguistics, 28, 495-514.

Mills, D. L., Coffey-Corina, S. A., \& Neville, H. J. (1993). Language acquisition and cerebral specialization in 20-month-old infants. Journal of Cognitive Neuroscience, 5(3), 317-334.

Mills, D. L., Plunkett, K., Prat, C., \& Schafer, G. (2005). Watching the infant brain learn words: Effects of vocabulary size and experience. Cognitive Development, 20(1), 19-31.

Musso, M., Moro, A., Glauche, V., Rijntjes, M., Reichenbach, J., Büchel, C., \& Weiller, C. (2003). Broca's area and the language instinct. Nature neuroscience, 6(7), 774-781.

Nazzi, T., Iakimova, G., Bertoncini, J., Frédonie, S., \& Alcantara, C. (2006). Early segmentation of fluent speech by infants acquiring French: Emerging evidence for crosslinguistic differences. Journal of Memory and Language, 54(3), 283-299.

Newport, E. L., \& Aslin, R. N. (2004). Learning at a distance I. Statistical learning of non-adjacent dependencies. Cognitive psychology, 48(2), 127-162.

Oberecker, R., Friedrich, M., \& Friederici, A. D. (2005). Neural correlates of syntactic processing in two-year-olds. Journal of Cognitive Neuroscience, 17(10), 1667-1678.

Pereyra, J. F. S., Klarman, L., Lin, L. J. F., \& Kuhl, P. K. (2005). Sentence processing in 30-monthold children: an event-related potential study. Neuroreport, 16(6), 645-648. 
Pisoni, D. B. (1993). Long-term memory in speech perception: Some new findings on talker variability, speaking rate and perceptual learning. Speech Communication, 13(1), 109-125.

Rivera-Gaxiola, M., Silva-Pereyra, J., \& Kuhl, P. K. (2005). Brain potentials to native and non-native speech contrasts in 7-and 11-month-old American infants. Developmental Science, 8(2), 162-172.

Saffran, J. R. (2003). Statistical language learning mechanisms and constraints. Current Directions in Psychological Science, 12(4), 110-114.

Schwartz, B. (2004). Why child L2 acquisition? In J. Van Kampen \& S. Baauw (eds.), Proceedings of Generative Approaches to Language Acquisition 2003, 47- 66. Utrecht, The Netherlands: LOT Occasional Series.

Silva-Pereyra, J., Rivera-Gaxiola, M., \& Kuhl, P. K. (2005). An event-related brain potential study of sentence comprehension in preschoolers: semantic and morphosyntactic processing. Cognitive brain research, 23(2-3), 247-258.

Skutnabb-Kangas, T. (1981). Bilingualism or not: The education of minorities. Clevedon, England: Multilingual Matters.

Sundara, M., Polka, L., \& Genesee, F. (2006). Language-experience facilitates discrimination of/d-/in monolingual and bilingual acquisition of English. Cognition, 100(2), 369-388.

Titone, R. (1989). On the Bilingual Person (Biblioteca Quademid'italianistica). Canadian Society for Italian Studies.

Ullman, M. T. (2001). A neurocognitive perspective on language: The declarative/procedural model. Nature Reviews Neuroscience, 2(10), 717-726.

Wartenburger, I., Heekeren, H. R., Abutalebi, J., Cappa, S. F., Villringer, A., \& Perani, D. (2003). Early setting of grammatical processing in the bilingual brain. Neuron, 37(1), 159-170.

Werker, J. F., \& Tees, R. C. (1984). Cross-language speech perception: Evidence for perceptual reorganization during the first year of life. Infant Behavior and Development, 7(1), 49-63.

White, L. \& Genesee, F. (1996) How native is near-native? The issue of ultimate attainment in adult second language acquisition. Second Language Research, 12, 233-265.

\section{AUTHOR BIODATA}

Asl Aktan-Erciyes is an Assistant Professor of Psychology at Kadir Has University, Istanbul. She received her Ph.D. in Developmental Psychology from Boğaziçi University, İstanbul under the supervision of Prof. Ayhan Aksu-Koç and Prof. Ali İ. Tekcan. She received her MA in Developmental Psychology again from Boğaziçi University. Dr. Aktan-Erciyes is interested in language and cognition interactions, and she uses bilingualism as a tool to study this interaction. One line of her research investigates how early and intense exposure to a second language affects the first language and vice versa. She is also interested in narrative development and event conceptualization. She follows a developmental perspective in her research and try to integrate converging evidence from multi-level sources. 